\title{
Retro-atlases II: a new edition of the first Statistical Atlas of Switzerland (1897)
}

\author{
Olaf König $^{\text {a }}$ \\ a Swiss Federal Statistical Office (FSO), olaf.koenig@bfs.admin.ch \\ * Corresponding author
}

Keywords: Thematic maps, Atlas

\begin{abstract}
:
In 2018, the Swiss Federal Statistical Office celebrated the 125th edition of its most prominent annual publication - the "Statistical Yearbook of Switzerland". This celebration was also an opportunity of reissuing as a supplement a selection of attractive, but not well-known visualisations from the first Statistical Atlas of Switzerland initially published in 1897 and yearbooks from the 19th century. The original atlas produced issued by the Swiss Federal Statistical Bureau contained 22 coloured "plates", including 6 maps and 16 diagrams. The techniques of visual display of statistical information were still in their infancy in statistical offices at this time, but this remarkable atlas already shows an expertise and judicious use of these techniques borrowed from the then reference book ${ }^{1}$ of Dr Georg von Mayr ${ }^{2}$. The foreword of the original atlas gives a clue of what the authors intended with this visual collection: their main objective was to democratise interest in public statistics and their results using visualisations. In an educational effort, also an explanatory preamble on the methods of graphical representation in general was offered.
\end{abstract}

The data used were relatively recent at the time of publication and the datasets even contain first long-time series, ranging from 1850 to 1898 . The themes addressed testify to the development of public statistics at the time and the historical context. We find the traditional demographic themes (birth rate, mortality, marriage, population structure, emigration and health), territorial aspects (surfaces and occupation and land use), political life (elected representatives and voting result), trade aspects (imports and exports) and the development of means of communications (railways, telegraph and telephone). The data visualisation techniques that were used already reflect a certain diversity: choropleth and proportional symbol maps, bar charts, pie charts, line charts and population pyramids, displayed as simple figures or as small multiples.

Following a similar first publication of a retro-atlas (The "Graphical-statistical Atlas 1914-2014"), published in 2015, he this latest atlas edition combines the 22 plates from the 1897 atlas as well as 7 older visualisations from the 1891-1899 yearbooks, and enriches this "retro" selection with their counterpart visualisations produced with recent data and modern tools around the year 2017. As the original atlas, the new atlas is fully bilingual and was printed in 2000 copies.

It is thus possible for the reader to compare different themes and developments in a broad historical perspective, as well as to appreciate the statistics bureau's early know-how in visual communication. This anniversary edition is therefore an opportunity to bring the first statistical atlas back to the public's attention, and to show the early interest of official statistics in this excellent "intuitive means of teaching, particularly suitable for popularising the interest in the work of statistics"3.

\footnotetext{
${ }^{1}$ Mayr, G. . (1874). Gutachten über die Anwendung der graphischen und geographischen Methode in der Statistik, erstattet von Ministerialrath Dr. Georg Mayr. München: Gedruckt bei J. Gotteswinter

${ }^{2}$ Director of the Statistical Office of the Kingdom of Bavaria and Professor at the University of Strasbourg

${ }^{3}$ Statistischen Bureau des eidg. Deparements des Innern. (1897). Graphisch-statistischer Atlas der Schweiz: Atlas graphique et statistique de la Suisse. Bern: Kümmerly \& Frey.
} 